\title{
VAULT FINALS ANALYSIS IN WOMEN'S ARTISTIC GYMNASTICS AT WORLD COMPETITIONS 2016-2019
}

\section{Ionuț CORLACI ${ }^{*}$, Ana-Maria GAVOJDEA ${ }^{1}$, Mihaela MANOS ${ }^{1}$, José FERREIRINHA ${ }^{2}$}

\footnotetext{
${ }^{1}$ National University of Physical Education and Sport, Faculty of Physical Education and Sport, Bucharest, Romania

${ }^{2}$ University of Trás-os-Montes and Alto Douro, Vila Real, Portugal

*Corresponding author: ionut_corlaci@yahoo.com
}

https://doi.org/10.35189/dpeskj.2020.59.4.8

\begin{abstract}
Women's Artistic Gymnastics manages to raise a great deal of interest from both spectators and $T V$ viewers. Though the Vault event has a short execution time, it is a highly dynamic and spectacular performance that makes it very attractive to the public. The preparation for those 5-7 seconds of performance on the vault apparatus must be very rigorous. Athletes need to be complete in terms of mastering their motor skills, showing courage, good spatial-temporal orientation and elegance. The final score depends on all of these elements. The reason for choosing the theme of this paper is to conduct an assessment of qualified athletes by nation and identify the vaults performed at world competitions in the vault apparatus finals between 2016 and 2019. The purpose is to identify and monitor for analysis the most complete athletes performing vaults during the apparatus finals. In addition, we would like to see whether there are any particular vaults or groups of vaults favoured by athletes in order to increase their advantage over other competitors. For this analysis, we used as research methods: bibliographic study, observation, monitoring and statistical analysis of the data collected from the processing and interpretation of the results achieved by our sample. Following the analysis conducted on the subjects of this research during the four years of study, we can conclude that the most complete athletes have at least two vaults of high technical value and increased difficulty in their sports portfolios.
\end{abstract}

Keywords: Women's Artistic Gymnastics, vault, high performance.

\section{Introduction}

Women's Artistic Gymnastics manages to raise a great deal of interest from both spectators and TV viewers. This has been proven by surveys and statistics on audience ratings, as well as an increased interest of media companies in advertising during this particular time slot.

The Vault event is short in terms of execution time (Farana \& Vaverka, 2012; Potop \& Toma-Urichianu, 2018; Kalinski et al., 2017), but with highly dynamic and spectacular performance. This makes it very attractive to the public.

The preparation for those 5-7 seconds of performance on the vault apparatus must be very rigorous; most vaults do not last more than 7 seconds on average (Kalinski et al., 2017; Kalinski et al., 2016). Athletes need to be complete in terms of mastering their motor skills, showing courage, good spatial-temporal orientation and elegance. The final score depends on all of these elements.

The International Gymnastics Federation (FIG), through the attributions of the Women's Technical Committee, replaced the traditional vaulting horse with an apparatus called "vaulting table" in 2001. Significant changes in the vaulting apparatus influenced the 
biomechanical structure of gymnast's technique (Sands \& McNeal, 2002). This change was made to provide safer vault performance after several gymnasts "rammed into the horse" or misplaced their hands during the 2000 Sydney Olympics (Kalinski et al., 2017).

In the Code of Points (FIG, 2013; FIG, 2016), vaults are divided into 5 groups:

1. Handspring, Yamashita, Round-off with or without turn in first and/or second flight phase;

2. Handspring forward with/without $1 / 1\left(360^{\circ}\right)$ in first flight phase - salto forward/ backward with/without longitudinal turn in second flight phase;

3. Handspring with $1 / 4-1 / 2\left(90^{\circ}-180^{\circ}\right)$ in first phase (Tsukahara) - salto backward with/ without turn in second flight phase;

4. Round-off (Yurchenko) with/without $3 / 4\left(270^{\circ}\right)$ turn in first flight phase - salto backward with/without turn in second flight phase;

5. Round-off with $1 / 2\left(180^{\circ}\right)$ turn in first flight phase - salto forward/backward with/without turn in second flight phase.

Of all these groups, Yurchenko vaults are favoured by gymnasts (Uzunov, 2010) but also researchers. These vaults have mainly been studied from a biomechanical standpoint and there is a wide variety of research dealing with all their phases, from the approach speed to landing.

According to the Code of Points, the Difficulty Value (DV) of each vault is predetermined based on the number of rotations (along the transversal and longitudinal axis in the first and second flight phase) and the intended body position - tucked, piked or stretched (Potop, 2013; Kalinski et al., 2017; Atikovic, 2012). Each vault in the Table of Vaults (FIG, 2013; FIG, 2016) is presented with its own number and predefined DV (Kalinski et al., 2017).

Regardless of their group or difficulty level, all vaults are divided into phases. Some authors (Prassas et al., 2006; Uzunov, 2010; Farana \& Vaverka, 2012; Potop, 2013; Stroescu, 2015; Potop \& Toma-Urichianu, 2018) consider that vaults have 6 phases: running, hurdle onto springboard, first flight, support with hands on table (handspring), second flight and landing. Other authors believe that a vault has 7 phases (Atikovic, 2012; Hedbavny \& Kalichova, 2015; Kalinski et al., 2016; Fernandes et al., 2016; Kalinski et al., 2017). The reason of disagreement is the springboard contact moment, when these authors claim there are 2 phases: flight onto springboard and springboard support. Of all these phases, only 4 are evaluated by judges: the 1st flight phase, the repulsion phase, the 2 nd flight phase and landing (Kalinski et al., 2016).

During qualifying rounds as well as finals of the vault apparatus competition, gymnasts must perform two vaults from distinctive groups and a different second flight phase. The final score of the performance on this apparatus is obtained as follows:

- The gymnast must perform two vaults, as mentioned above, from two separate groups and a different second flight phase;

- After executing each vault, the gymnast is evaluated by the apparatus jury;

- Based on the athlete's competitive performance for both vaults, apparatus judges award scores;

- The score for each of the two vaults is used to calculate their arithmetical average; 
- The average of the two scores is the final score. (FIG, 2013; FIG, 2016);

- Athletes are ranked in descending order, with the winner having the best score.

The highly kinaesthetic sense that gymnasts have developed for the vault apparatus provides the possibility of an extensive training volume by performing a great number of vaults during workouts. Through an increased volume of repetitions, gymnasts develop their routines. Training efficiency is achieved and becomes visible when gymnasts prove their adaptability to specific effort at a certain moment during the training session. At the same time, precision through vaulting confidence and accuracy are necessary, indispensable and sufficient proofs that gymnasts can overcome all obstacles (emotion-courage, precisionconfidence and so on) by adequate training adjustment.

All gymnasts around the world are preparing through training. All athletes consider their training efficient and useful for achieving great performance. But it is not always so. We need take into account a wide variety of factors.

To highlight these factors, we will point out that the long-term training process of the athlete includes long- and short-term adaptability, overtraining, de-adaptation and readaptation (Platonov, 2015).

Long-term adaptation occurs progressively as a result of a prolonged or repetitive action of certain stimulating agents on the athlete's body. Essentially, long-term adaptation develops based on repeatedly achieving short-term adaptation and, due to the gradual quantitative accumulation of certain changes, is characterised by the fact that the body shifts from a nonadapted to an adapted state, thus acquiring a new skill. (Platonov, 2015)

Short-term adaptation is an athlete's ability to self-adjust once for a relatively short time, under increased exercise intensity. The functions of various organs, systems and mechanisms are activated immediately after starting the effort. This leads the body's functional exercise capacity to efficiently solve a task. The blood supply to the muscles is increased, resulting in the build-up of metabolic products and rapid depletion of energy substances like phosphocreatine and muscular glycogen. Stopping the activity triggers short-term adaptation reversal processes. During a short period, all the body's functions and systems, including those dealing with energy, return to the previous level. After high-intensity training programmes that cause obvious fatigue, recovery processes cause depletion of muscle glycogen reserves. This situation can last even two or three days. (Platonov 2015)

One should take into consideration that the formation of short-term adaptation for certain motor actions, which is manifested as changes in the parameters of functional systems that are rational in size and have particular interaction characteristics, does not mean that stable adaptation has occurred.

We emphasise that a particular feature of a properly adapted functional system is its extraordinary mobility and stability in achieving an identical final result while being subjected to different internal and external environmental conditions.

By comparing short-term to long-term adaptation, we point out that transitioning from the quick yet largely unfinished shifting phase to the long-term one represents a crucial moment of the adjustment process, because it confirms that efficient adaptation to external environmental factors has occurred.

To attain efficiency by shifting from short-term to guaranteed long-term adaptation, an important process must take place within the functional system. This process is related to a 
structural and functional complex of changes in the body, which ensures the system's development, setup and power increase to fulfil certain requirements.

The high-performance athlete's body positively responds to adjustment reactions and, after interrupting intense training, is much more exposed to de-adaptation than a less trained and lower-performing athlete. This fact does not take into account training breaks that exceed one week after each macrocycle and two weeks after a full year. Even during these training breaks, athletes will not rest in an exclusively passive manner but will engage in two or three one-hour sessions to maintain those components that are more likely to be exposed to deadaptation.

According to Rojas-Barrionuevo et al. (2017), "high-performance gymnasts have to undertake demanding training programmes, with a high number of hours per session and a large volume of repetitions of high intensity exercises which provoke a significant overload of certain systems and muscle groups" (p. 729).

It may be essential for the athlete to train in cycles in order to induce optimal improvements and prevent overtraining. Without sufficient recovery time, adaptation may not occur and the athlete may develop the symptoms of overtraining due to continuous and/or excessive exposure to training stress. (Fry et al., 1992)

Overtraining is caused by excessive exercise that goes beyond the athlete's adaptation abilities. The state of overtraining is the result of over-planning and a lack of correlation between effort, rest and diet. According to Meeusen et al. (2006) as well as Budgett (1998), overtraining syndrome is a very specific and severe condition when overtraining without adequate rest and recovery leads to performance decrements that last more than 2-3 months, coupled with a mood disturbance.

It is desirable to avoid overtraining. Restoring the athlete's balance by inadequate recovery is much more damaging and drains far more resources.

"Musculoskeletal overtraining may occur as a result of inappropriate physiological, biomechanical or anatomical stresses. Appropriate stresses to the musculoskeletal system cause positive adaptation. Inappropriate volume or intensity of exercise may cause a maladaptive cellular or tissue response due to an imbalance between load and recovery." (Vain \& Kums, 2002, pp. 329-330)

The reason for choosing the theme of this paper is to conduct an assessment of qualified athletes by nation and identify the vaults performed at world competitions in the vault apparatus finals between 2016 and 2019.

What are the favourite vaults of top gymnasts? Is there only one or several groups of vaults, is there a certain vault or others that can guarantee winning a world competition once the gymnast acquires the skill and performs it?

The purpose is to identify and monitor for analysis the most complete athletes performing vaults during the apparatus finals. In addition, we would like to see whether there are any particular vaults or groups of vaults favoured by athletes in order to increase their advantage over other competitors. 


\section{Methodology}

For this analysis, we used as research methods: bibliographic study, observation, monitoring and statistical analysis of the data collected from the processing and interpretation of the results achieved by our sample.

\section{Research duration, site and sample}

The study was conducted over a period of four years, which included the greatest world events of Women's Artistic Gymnastics between 2016 and 2019. The research was limited by the interruption and postponement of all competitions worldwide, including the 2020 Olympics, due to the COVID pandemic.

The investigated sample consists only of women gymnasts, each representing a nation and being qualified for the final round of the vault apparatus competition.

The following competitions were monitored: 2016 Olympics, Rio de Janeiro - Brazil (Table 1); 2017 World Championships (WC), Montreal - Canada (Table 2); 2018 World Championships, Doha - Qatar (Table 3); 2019 World Championships, Stuttgart - Germany (Table 4).

\section{Results}

In compliance with the European General Data Protection Regulation (GDPR) legislation, we will encode the names of all gymnasts participating in our study in order to protect their identities.

Each athlete performs two vaults. Each vault has a code and all of them can be found in the Code of Points for Women's Artistic Gymnastics (FIG, 2013; FIG, 2016). The code indicates the group of vaults as well as the particular type of vault being performed.

Table 1. Subjects and their results at the Rio 2016 Olympics

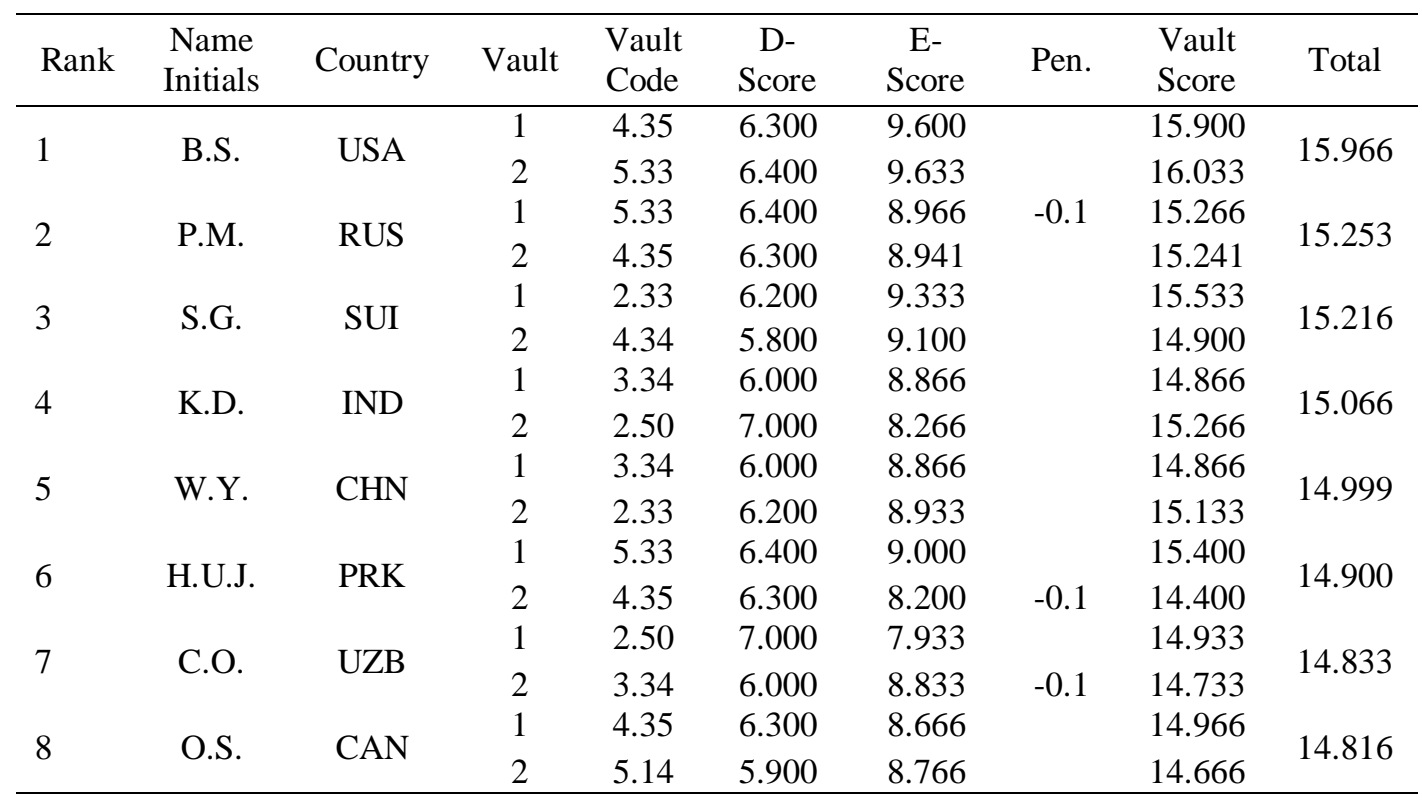


The complexity and difficulty of each vault are evaluated by judges and centralised in the D-Score column. The jury establishes whether the vaults executed by gymnasts comply with certain biomechanical parameters of direction and amplitude.

Table 2. Subjects and their results at the 2017 WC, Montreal - Canada

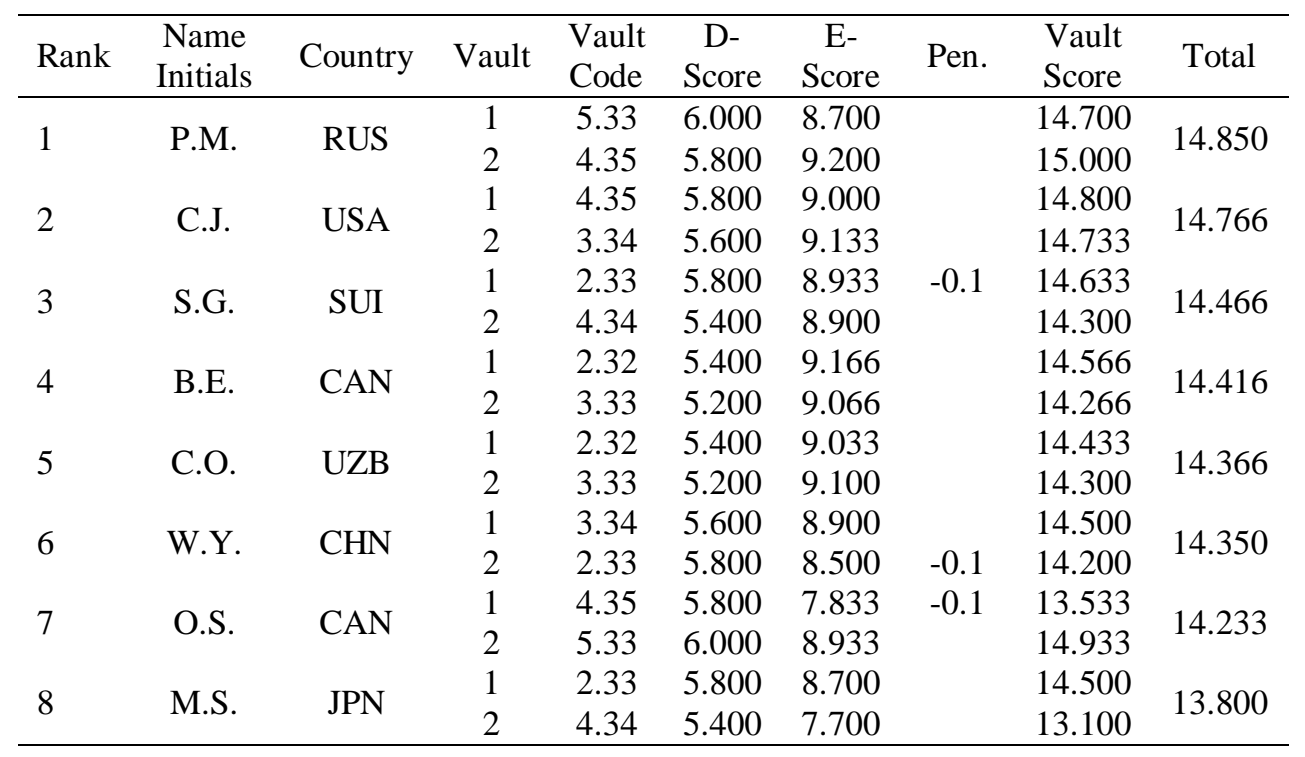

The elegance and precision in executing a vault are evaluated by the E-panel jury and centralised in the corresponding column. Vault performance is evaluated by deduction from a maximum score of 10.00. Starting with this value, penalties are deducted for poor technique, behaviour faults, number of steps taken after landing or even falls.

Table 3. Subjects and their results at the 2018 WC, Doha - Qatar

\begin{tabular}{|c|c|c|c|c|c|c|c|c|c|}
\hline Rank & $\begin{array}{l}\text { Name } \\
\text { Initials }\end{array}$ & Country & Vault & $\begin{array}{l}\text { Vault } \\
\text { Code }\end{array}$ & $\begin{array}{c}\text { D- } \\
\text { Score }\end{array}$ & $\begin{array}{c}\text { E- } \\
\text { Score }\end{array}$ & Pen. & $\begin{array}{l}\text { Vault } \\
\text { Score }\end{array}$ & Total \\
\hline \multirow{2}{*}{1} & \multirow{2}{*}{ B.S. } & \multirow{2}{*}{ USA } & 1 & 5.33 & 6.000 & 9.266 & & 15.266 & \multirow{2}{*}{15.366} \\
\hline & & & 2 & 4.35 & 5.800 & 9.666 & & 15.466 & \\
\hline \multirow{2}{*}{2} & \multirow{2}{*}{ O.S. } & \multirow{2}{*}{ CAN } & 1 & 5.33 & 6.000 & 8.600 & & 14.600 & \multirow{2}{*}{14.516} \\
\hline & & & 2 & 4.34 & 5.400 & 9.033 & & 14.433 & \\
\hline \multirow{2}{*}{3} & \multirow{2}{*}{ M.A. } & \multirow{2}{*}{ MEX } & 1 & 2.33 & 5.800 & 8.800 & \multirow{4}{*}{-0.1} & 14.600 & \multirow{2}{*}{14.508} \\
\hline & & & 2 & 3.34 & 5.600 & 8.916 & & 14.416 & \\
\hline \multirow{2}{*}{4} & \multirow{2}{*}{ C.O. } & \multirow{2}{*}{ UZB } & 1 & 2.33 & 5.800 & 8.600 & & 14.400 & \multirow{2}{*}{14.300} \\
\hline & & & 2 & 3.33 & 5.200 & 9.000 & & 14.200 & \\
\hline \multirow{2}{*}{5} & \multirow{2}{*}{ Y.S. } & \multirow{2}{*}{ KOR } & 1 & 2.33 & 5.800 & 8.833 & \multirow[t]{2}{*}{-0.1} & 14.533 & \multirow{2}{*}{14.233} \\
\hline & & & 2 & 4.34 & 5.400 & 8.533 & & 13.933 & \\
\hline \multirow{2}{*}{6} & \multirow{2}{*}{ L.J. } & \multirow{2}{*}{$\mathrm{CHN}$} & 1 & 3.34 & 5.600 & 8.600 & \multirow[t]{4}{*}{-0.1} & 14.100 & \multirow{2}{*}{14.150} \\
\hline & & & 2 & 2.33 & 5.800 & 8.400 & & 14.200 & \\
\hline \multirow{2}{*}{7} & \multirow{2}{*}{ B.E. } & \multirow{2}{*}{ CAN } & 1 & 2.32 & 5.400 & 8.600 & & 14.000 & \multirow{2}{*}{14.116} \\
\hline & & & 2 & 3.33 & 5.200 & 9.033 & & 14.233 & \\
\hline \multirow{2}{*}{8} & \multirow{2}{*}{ P.R.Y. } & \multirow{2}{*}{ PRK } & 1 & 4.35 & 5.800 & 7.566 & \multirow[t]{2}{*}{-0.3} & 13.066 & \multirow{2}{*}{13.616} \\
\hline & & & 2 & 2.33 & 5.800 & 8.366 & & 14.166 & \\
\hline
\end{tabular}

In the penalty column, we recorded the deductions for landing deviations outside of the regulated area. This landing area is a clearly defined trapezoid with its shorter base of $1.5 \mathrm{~m}$ 
located near the vaulting table and a longer base of $3 \mathrm{~m}$ on the opposite side. Depending on the number of steps taken by gymnasts outside of the landing area, Line Judges give additional penalties. Between 3 and 4 gymnasts per competition received penalties. Here, we took into account all competitions during the experiment.

Table 4. Subjects and their results at the 2019 WC, Stuttgart - Germany

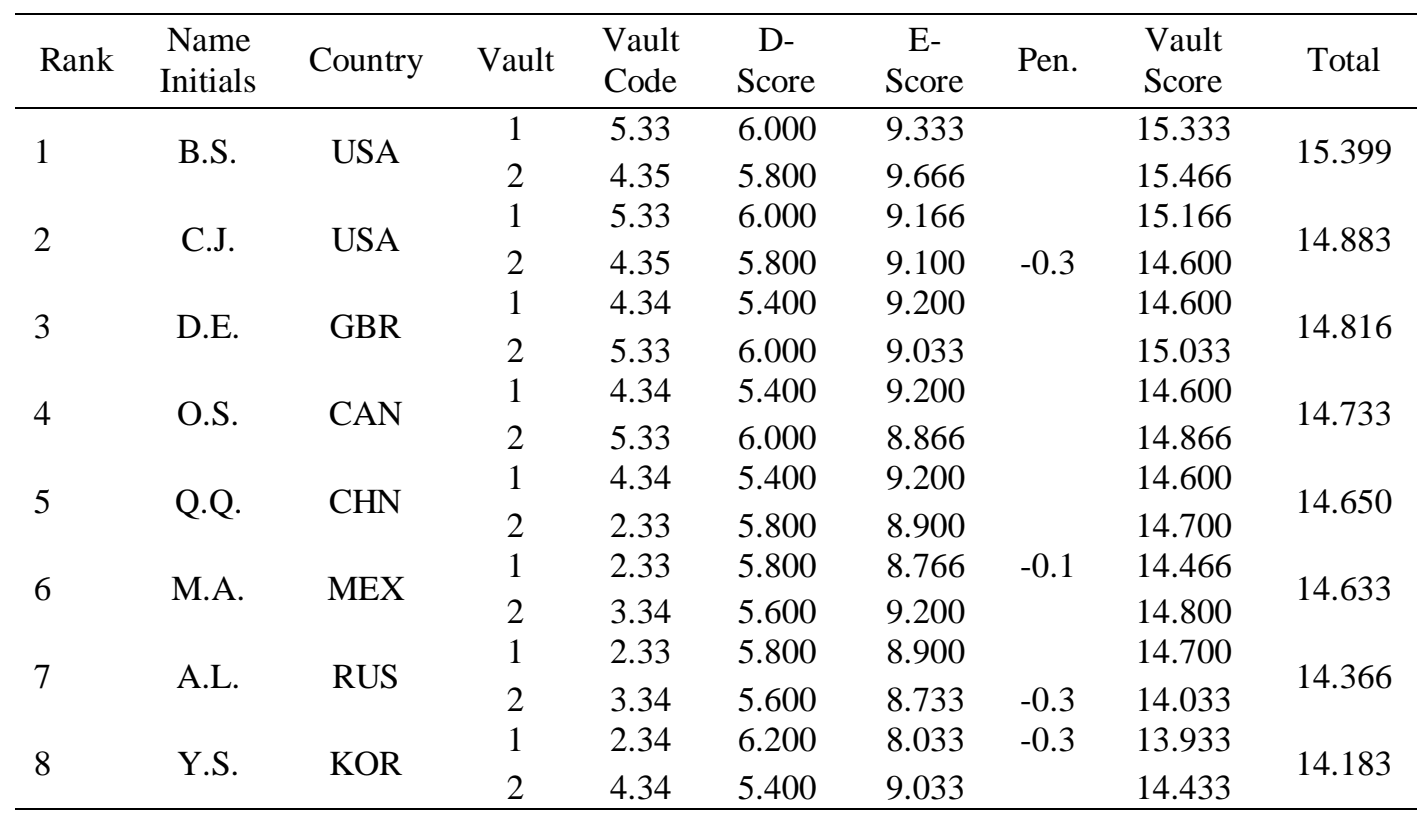

In the last two columns, we recorded the final score for each of the gymnast's two vaults. The final score for a vault is the sum of scores awarded by D-panel and E-panel juries. The arithmetic average of both vault scores is the final score. The winner will have the highest score.

Figure 1 reveals that only four out of the five vault groups are accessed by finalist gymnasts. Group 1 vaults are totally missing in all four major competitions between 2016 and 2019.

In total, ten vaults from groups 2, 3, 4 and 5 were performed as follows:

- four vaults from group 2, representing $40 \%$ of the total accounted groups;

2.32 - Handspring forward on - stretched salto forward with $1 / 1$ turn $\left(360^{\circ}\right)$ off;

2.33 - Handspring forward on - stretched salto forward with $1 \frac{1}{2}$ turn $\left(540^{\circ}\right)$ off;

2.34 - Handspring forward on - stretched salto forward with $2 / 1$ turn $\left(720^{\circ}\right)$ off (it bears the gymnast's name and was first performed at the 2019 Korea Cup);

2.50 - Handspring forward on - tucked double salto forward off;

- two vaults from group 3, representing $20 \%$ of the total accounted groups;

3.33 - Tsukahara stretched with $1 \frac{1}{2}$ turn $\left(540^{\circ}\right)$ off;

3.34 - Tsukahara stretched with $2 / 1$ turn $\left(720^{\circ}\right)$ off;

- two vaults from group 4, representing $20 \%$ of the total accounted groups;

4.34 - Round-off, flic-flac on - stretched salto backward with $2 / 1$ turn $\left(720^{\circ}\right)$ off;

4.35 - Round-off, flic-flac on -stretched salto backward with $2 \frac{1 / 2}{2}$ turn $\left(900^{\circ}\right)$ off;

- two vaults from group 5, representing $20 \%$ of the total accounted groups; 
5.14 - Round-off flic-flac with $1 / 2$ turn $\left(180^{\circ}\right)$ - tucked salto forward with $1 \frac{1 / 2}{2}$ turn $\left(540^{\circ}\right)$ off (in the Code of Points 2017-2020, it has the code 5.13) (FIG, 2016);

5.33 - Round-off flic-flac with $1 / 2$ turn $\left(180^{\circ}\right)$ on - stretched salto forward with $1 \frac{1}{2}$ turn $\left(540^{\circ}\right)$ off.

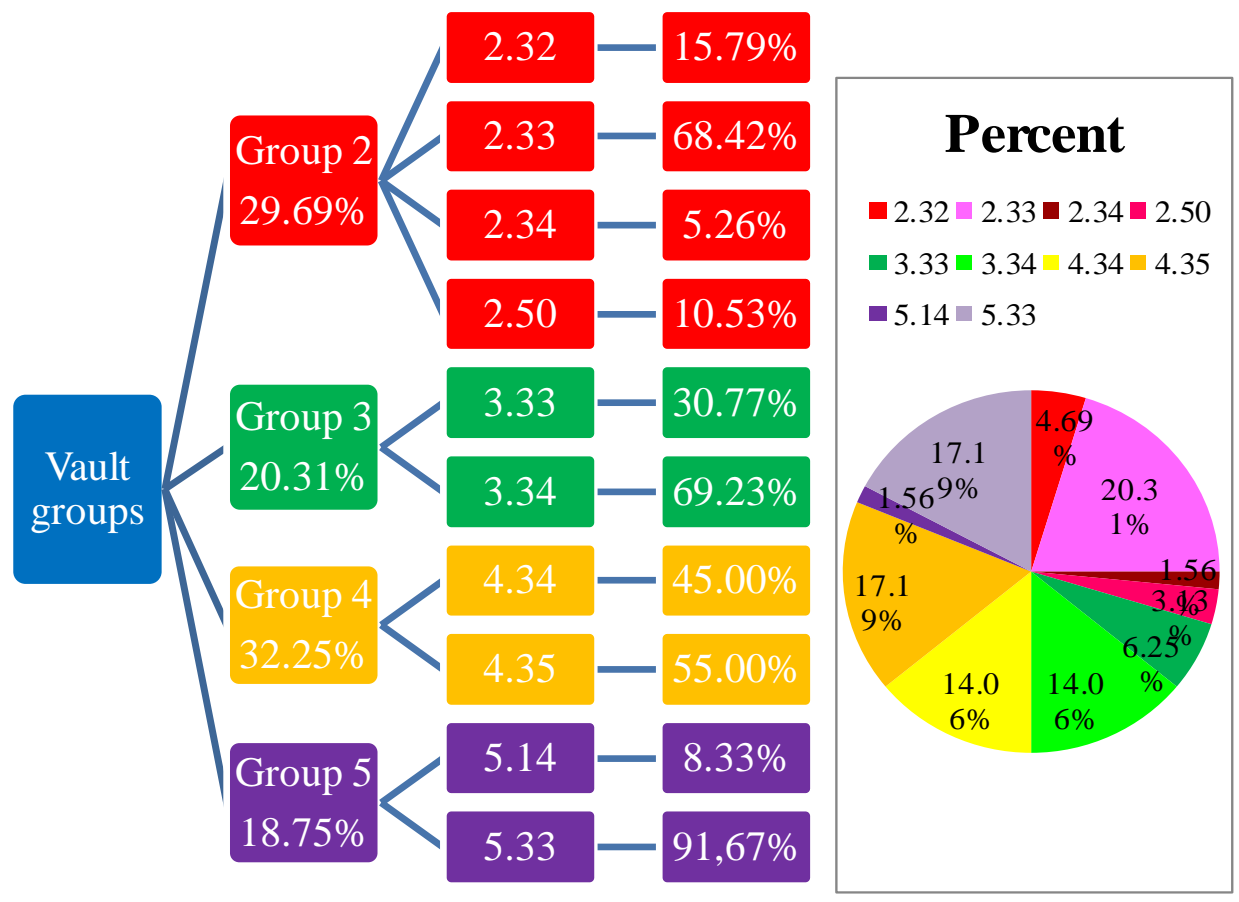

Figure 1. Vault dispersion per group

Figure 2. Vault dispersion graph

Figure 2 shows the graphical charts representing the percentages of the total vaults executed by the 18 gymnasts participating in the research. Vaults from group 2 have an increased difficulty but are accessible to the majority of gymnasts, unlike vaults from group 5 (5.14) that can be performed by only one athlete.

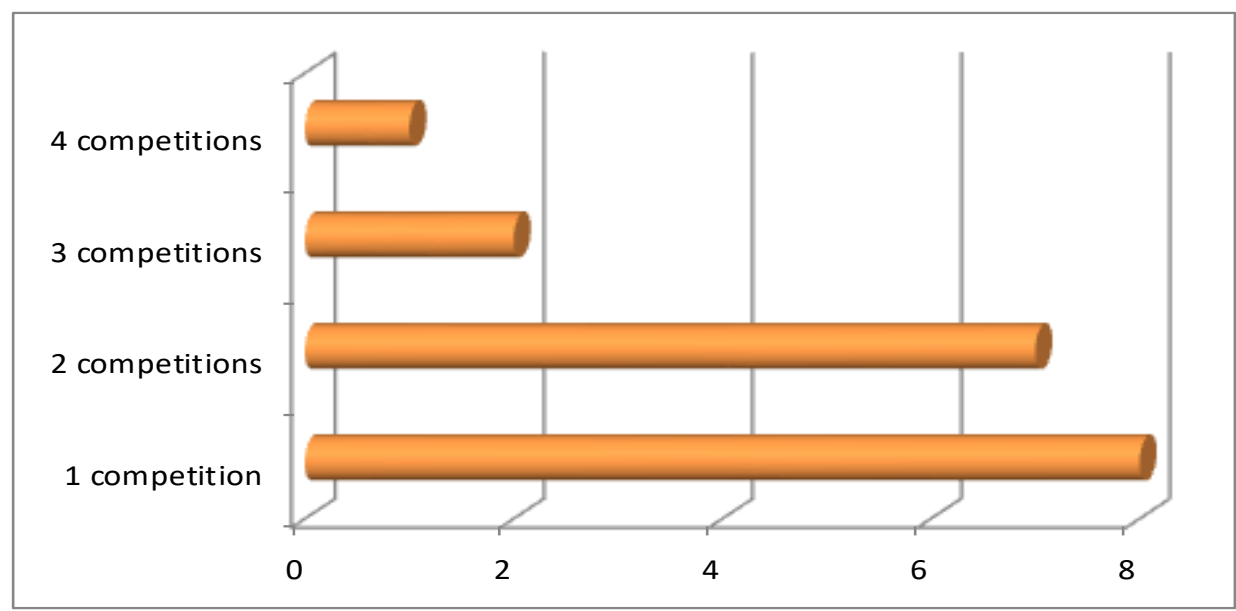

Figure 3. Frequency of participation in the four monitored competitions 
Eighteen gymnasts took part in all four competitions. As shown in Figure 3, 8 gymnasts participated in one major competition, 7 gymnasts took part in two competitions, 2 gymnasts, in three competitions, and only one gymnast engaged in all four competitions analysed in this paper.

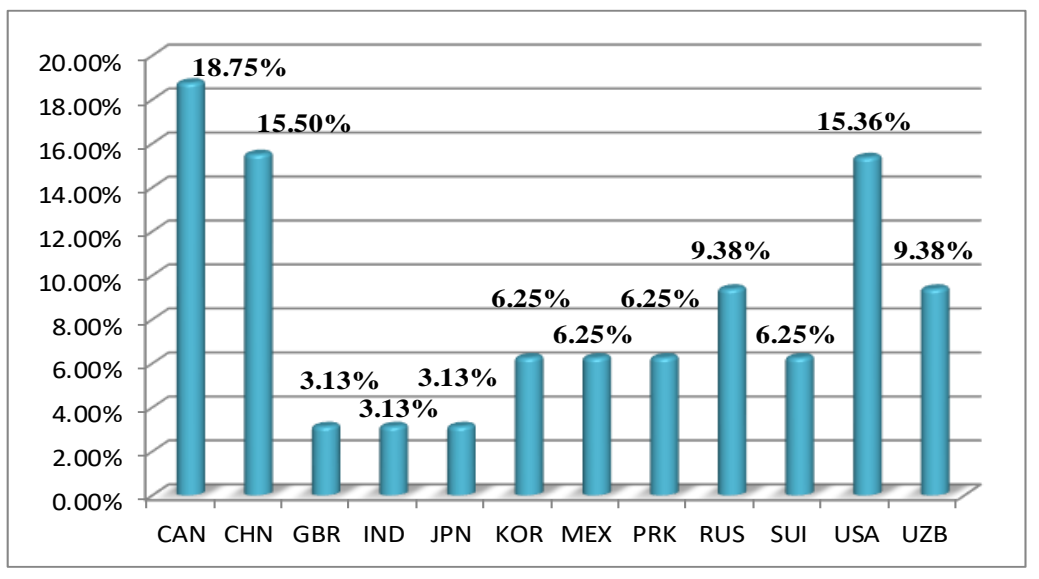

Figure 4. Percentage participation in the competition finals by country

There were 12 countries with representatives in the final competitions of the Vault event. Only the United States of America, Canada and China had more than one representative in the finals (Figure 4). In an apparatus final, one country can have no more than 2 gymnasts. In fact, these three countries are way ahead of all the others.

On the opposite end, countries like Great Britain, India and Japan had only one finalist throughout the period concerned.

As a consequence of changes in competition regulations over the last ten years, countries with a more recent tradition and less experience have gained access to and engaged in Women's Artistic Gymnastics competitions.

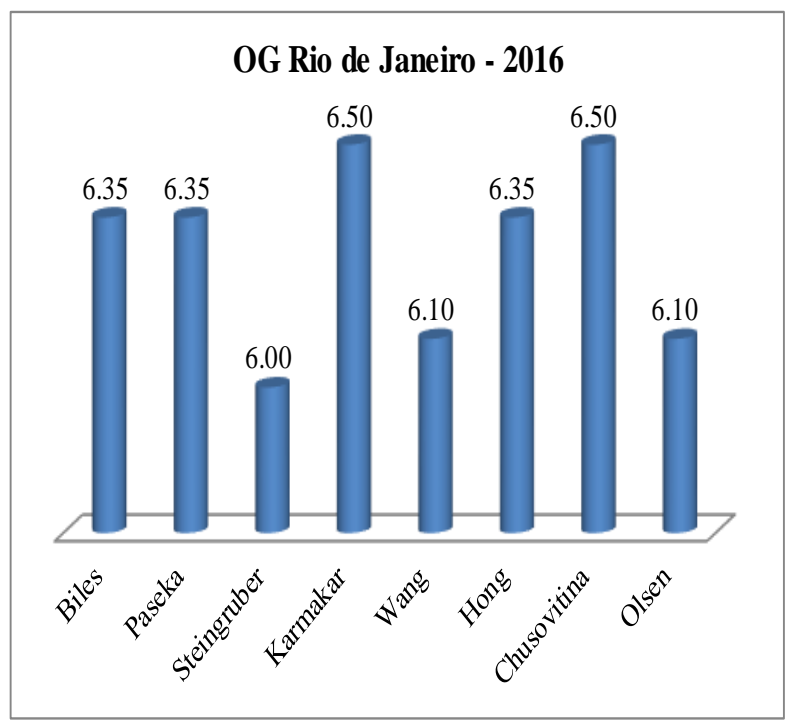

Figure 5. D-score arithmetic average for gymnasts in 2016

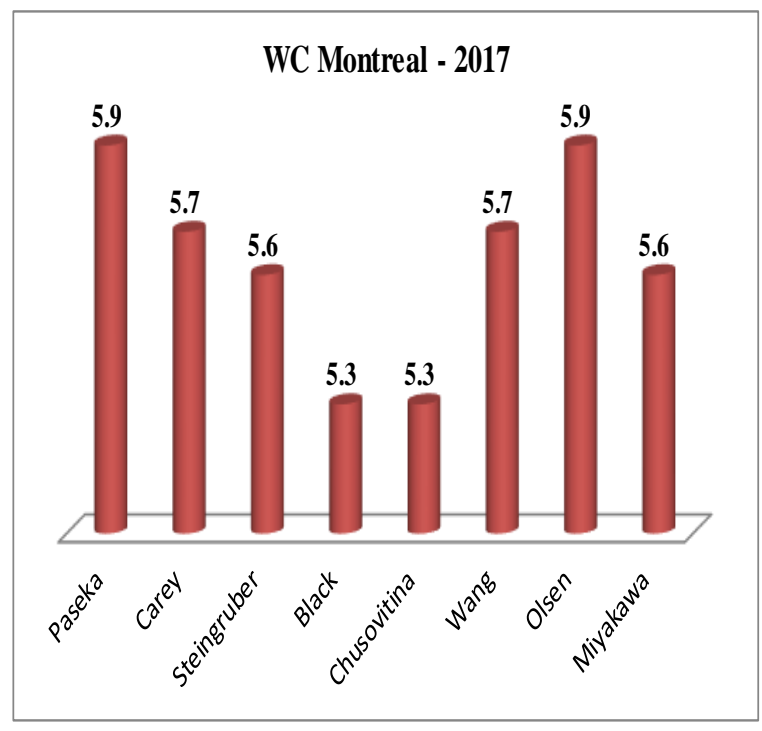

Figure 6. D-score arithmetic average for gymnasts in 2017 
Though we can clearly see that the starting scores in Rio 2016 (Figure 5) are higher than in other competitions (Figures 5, 6, 7 and 8), the differences are due to changes operated to the Code of Points since 2017. These modifications devalued the starting score of many vaults and did it in a different yet uneven way. During the four years of study, it has been interesting to discover that difficulty has a sinusoidal shape.

A high level was to be expected at the 2016 Olympic Games. The same high level was kept in 2017, when the individual apparatus competition gave some gymnasts the opportunity to take risks and execute new vaults that were not always completely mastered. It was a moment when athletes could prove their worth. They were no longer under pressure to support their teams with constant performance.

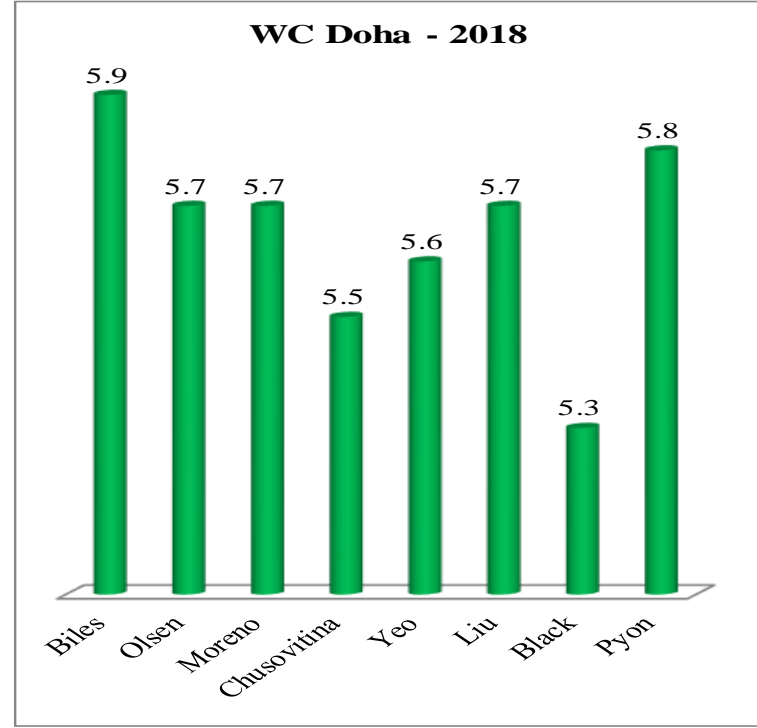

Figure 7. D-score arithmetic average of gymnasts in 2018

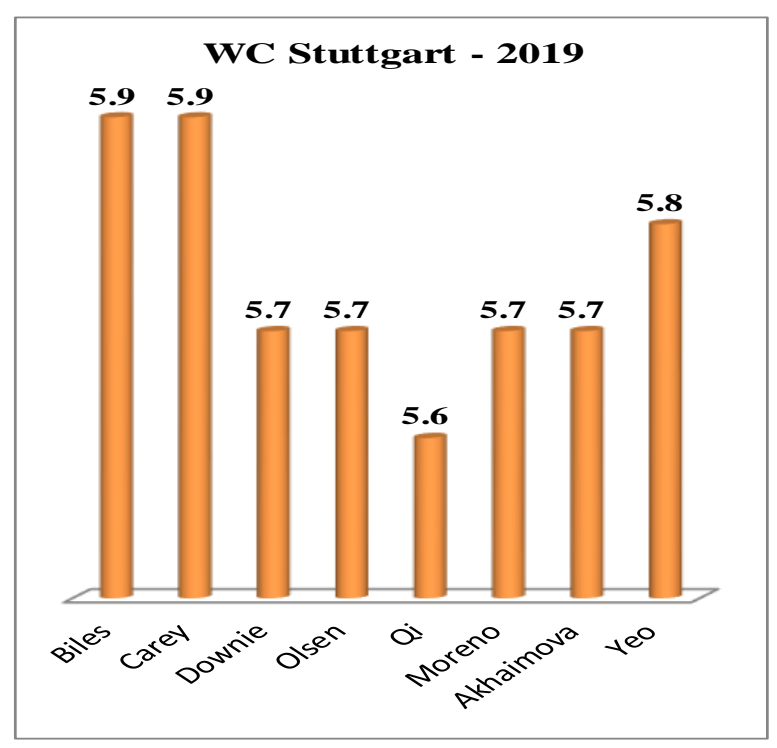

Figure 8. D-score arithmetic average of gymnasts in 2019

For all gymnasts, regardless of each one's level and worth, 2018 is a year of preparation and growth, of increased difficulty and quality of execution. In order to achieve their objectives and aim for the winner's podium during this Olympic cycle, the national teams of competing countries have to choose their gymnasts and the difficulty of exercises and vaults for maximum efficiency in future competitions. There are still athletes who have inconsistent performance (Figure 7).

During 2019, we can notice that the values of performed vaults have become more balanced (Figure 8), meaning that athletes have increased their difficulty. The difference in value between the vaults executed by gymnasts is only 0.30 points. Given that this is a slight gap, the difference needed to get to the winner's podium largely depends on the quality of execution. 


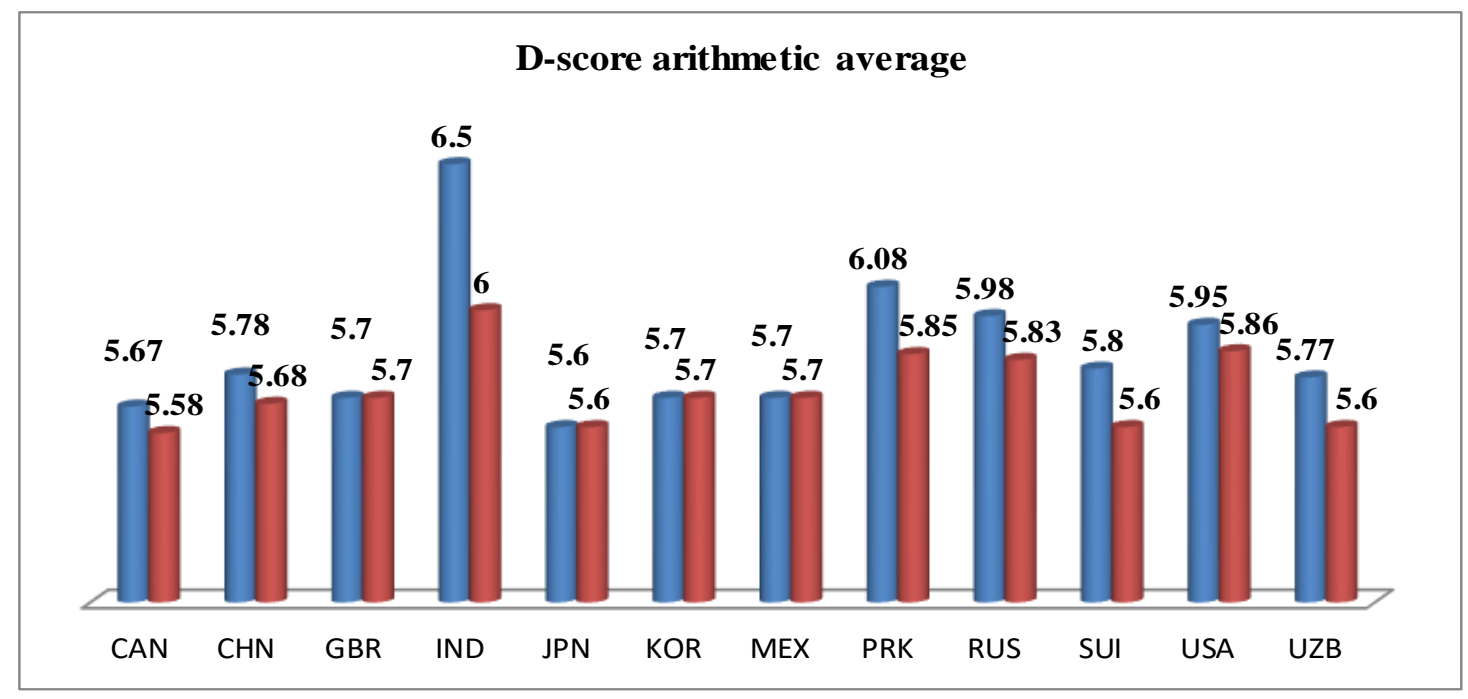

Figure 9. D-score arithmetic average of participating countries, 2016-2019

Specifically, after each Olympic cycle, the FIG Women's Technical Committee operates changes to the Code of Points. These changes can be observed in Figure 9, where the blue column (average results for vault difficulty recorded at the 2016 Rio Olympics) is, in most cases, higher than the red column (average results for vault difficulty recorded between 2017 and 2019).

The FIG Women's Technical Committee took into account that gymnasts with valuable vault portfolios were favoured and had created for themselves an unrivalled advantage over other competitors in both all-around events and vault apparatus finals. Therefore, after 2017, the D-score value gap between vaults has decreased considerably. We can easily observe that the most valuable vaults have decreased to the level of the majority of competitors.

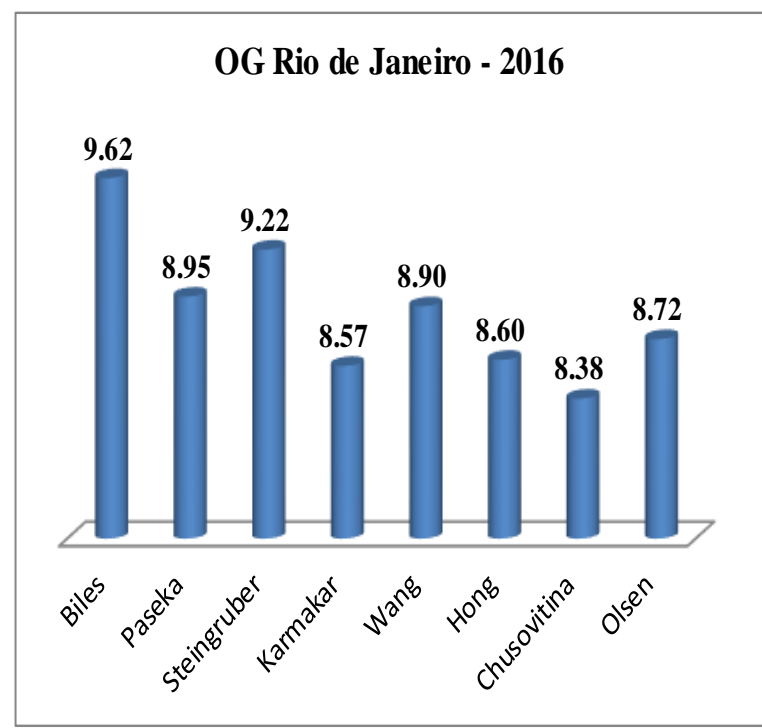

Figure 10. E-score arithmetic average of gymnasts in 2016

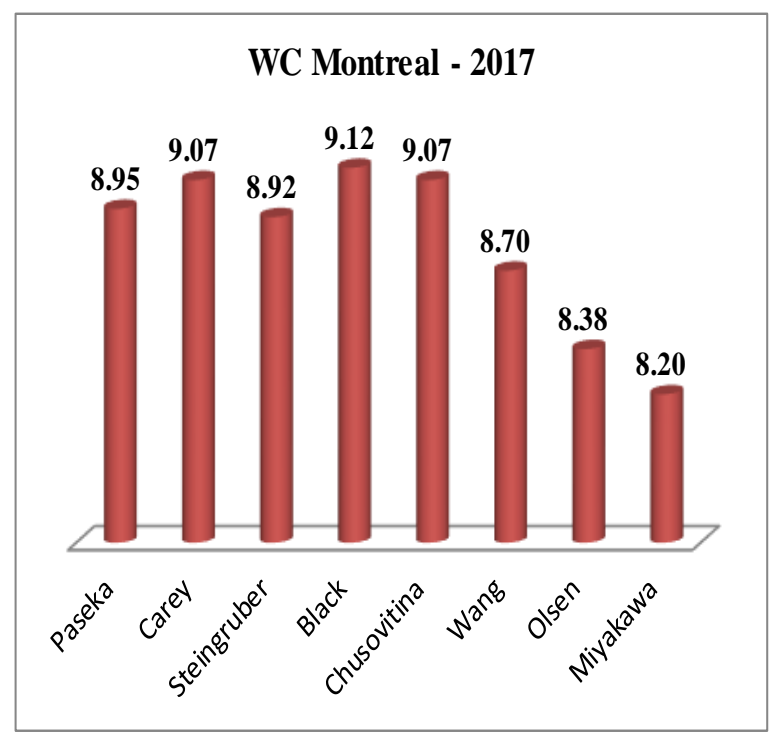

Figure 11. E-score arithmetic average of gymnasts in 2017 
Figure 10 shows that finalists at the 2016 Rio Olympics had many execution faults but were within a margin of 1.24 points. Our interpretation is that gymnasts were emotional, favoured taking risks and executed insufficiently mastered vaults. The E-panel jury deducted technical faults, behaviour faults and steps after landing. On the other hand, in Montreal, in 2017, gymnasts improved their vaults and managed to decrease the margin to 0.92 points (Figure 11).

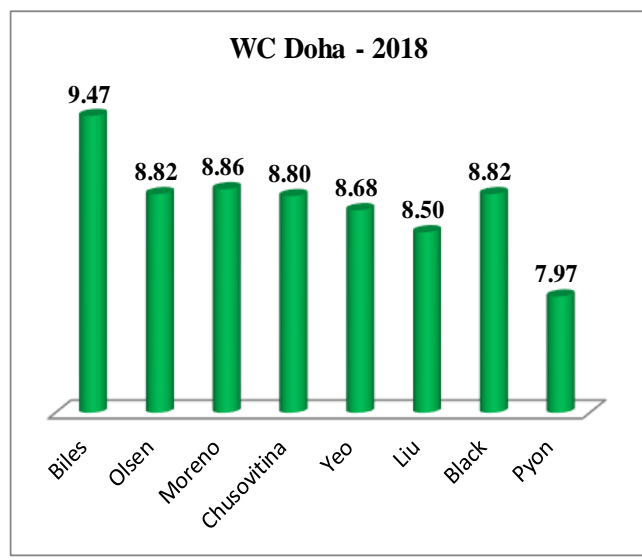

Figure 12. E-score arithmetic average of gymnasts in 2018

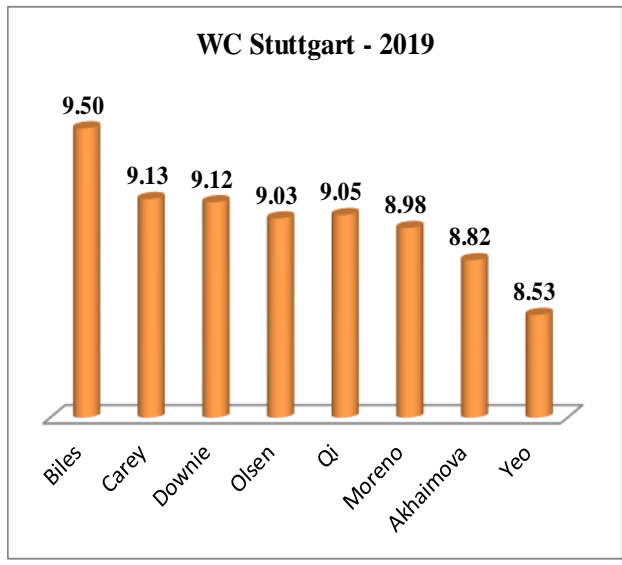

Figure 13. E-score arithmetic average of gymnasts in 2019

At the 2018 Doha competition, the participating gymnasts also made many mistakes (Figure 12) in vault execution. Only one athlete succeeded in getting a score above 9 points. The worst athlete got a 2.03 deduction, highlighting that gymnasts needed to improve their vaults. In Stuttgart, in 2019 (Figure 13), five out of eight vaults received a score above 9, resulting in a deduction of less than 1 point. The second and third places show a very tight score difference of only 0.01 points. Consequently, it is even harder to discern from a spectator's point of view. The worst performed vault received a 0.47 deduction from the judges. We do notice that gymnasts are very close to perfecting their vaults also from the execution perspective.

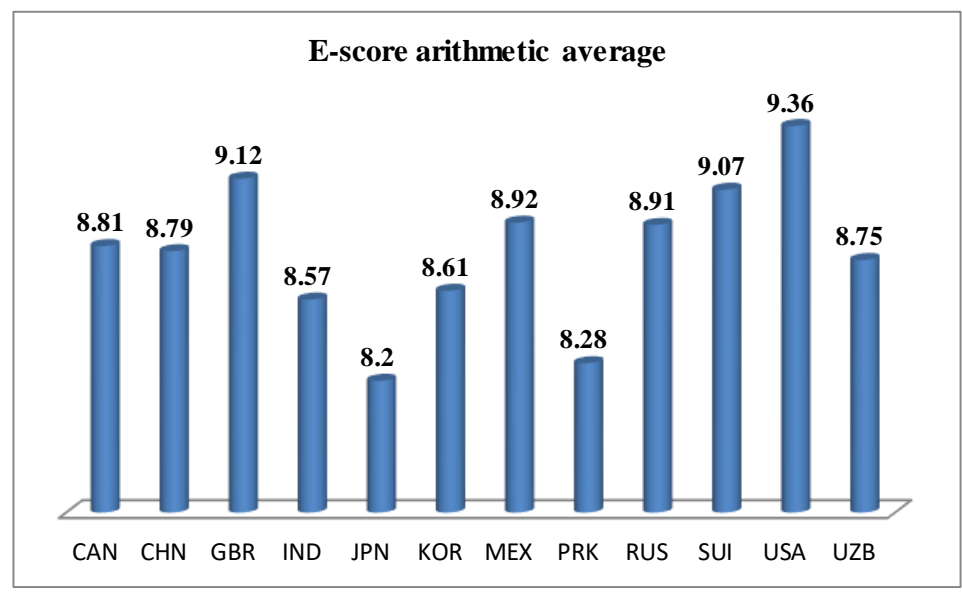

Figure 14. E-score arithmetic average of participating countries, 2016-2019 
Figure 14 shows the average of execution deductions during the entire four-year period of our experiment. We can say the following: there were several gymnasts who participated in one competition, but there was only one who participated in all competitions; the most consistent and obviously the most efficient was the US athlete; during the entire period of the experiment, only 3 of the 8 gymnasts succeeded in having constant performance and getting above 9.00 points for execution.

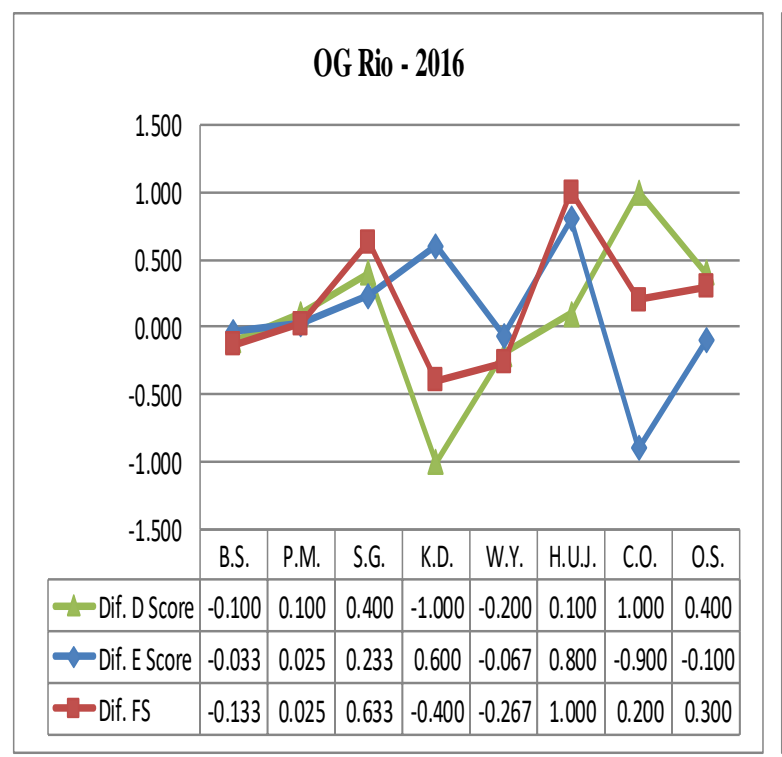

Figure 15. D-score differences between the first and second vaults - 2016

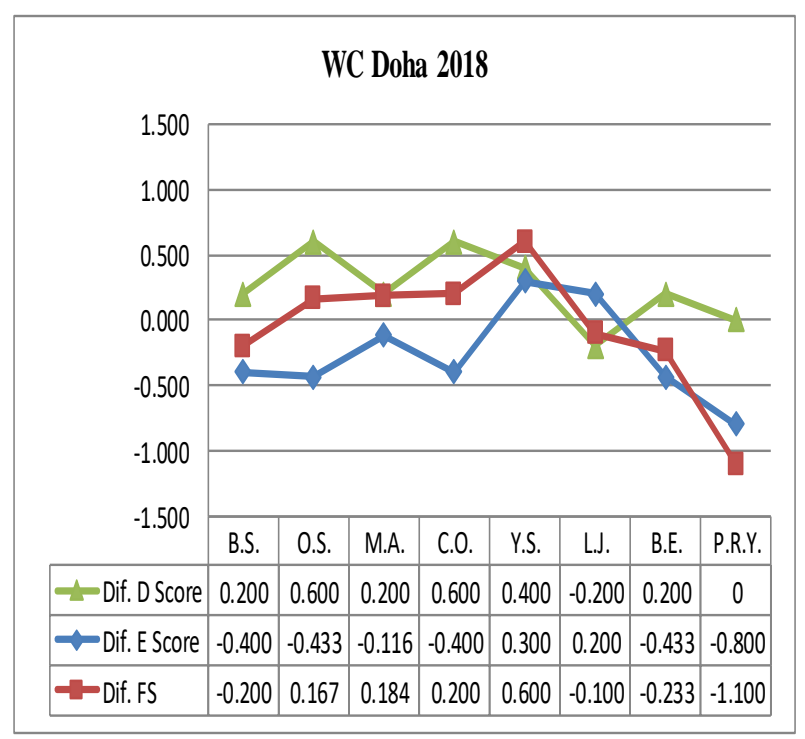

Figure 17. D-score differences between the first and second vaults - 2018

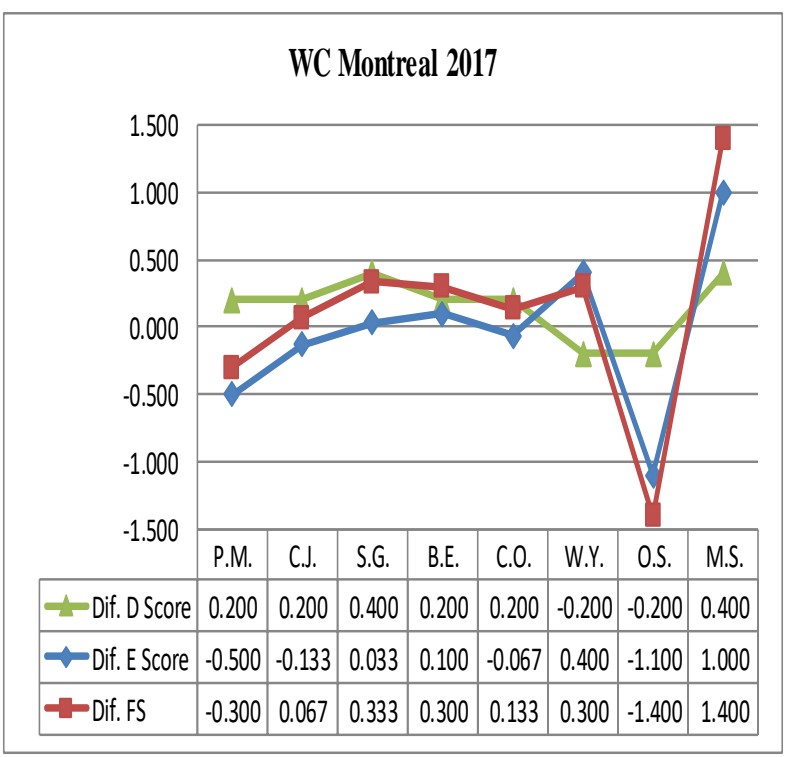

Figure 16. D-score differences between the first and second vaults - 2017

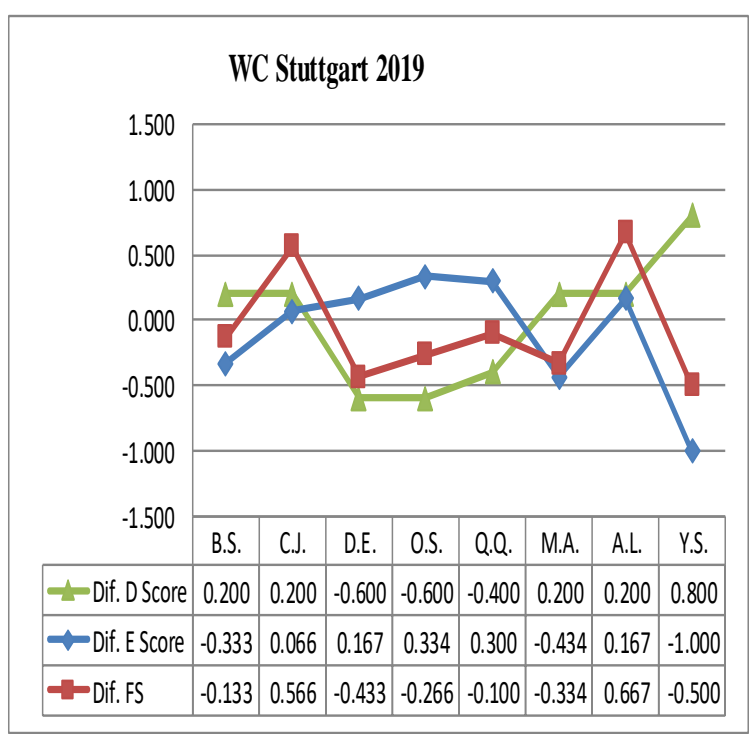

Figure 18. D-score differences between the first and second vaults - 2019

Figures 15-18 show the D-score differences between the first and second vaults, the Escore differences between the first and the second vaults as well as the final scores for each of 
the two vaults, for each competition and gymnast. So, in Figure 15, 5 gymnasts executed a first vault with a higher difficulty value at the 2016 Olympic Games in Rio. For the two vaults, the widest difference was 1 point, and the lowest difference was 0.100 points. Four gymnasts had a better execution on their first vault, and 4 gymnasts had a better execution on their second vault - the widest differences were -0.900 points (the second vault was better executed than the first) and 0.800 points (the execution of the first vault was better). Regarding the final score differences, 5 gymnasts received a higher score for their first vault compared to the second, the widest difference being 1 point. We can also see that 5 gymnasts (B.S., P.M., S.G., W.Y. and O.S) have relatively tighter score differences (lower than 0.500 points), while the other 3 competing gymnasts have wider differences: K.D. has 1.600 points (-1.000 point difference between $\mathrm{D}$-scores and +0.600 points difference between E-scores), H.U.J. has 0.900 points $(0.100$ points difference between $\mathrm{D}$-scores and 1.000 point difference between final scores), and C.O. has 1.900 points (-0.900 points difference between E-scores and +1.000 point difference between D-scores).

Figure 16 shows the results achieved at the 2017 World Championships in Montreal. We notice that 6 gymnasts had a higher difficulty value on their first vault, the widest difference between the two vaults being 0.400 points, while the other differences are 0.200 points (both in favour of the first vault and the second one); 4 gymnasts had a better first vault execution, and 4 gymnasts had a better second vault execution, the widest differences being -1.100 points (the second vault was better than the first in terms of execution) and 1.000 point (the first vault execution was better); regarding the final score, 6 gymnasts received a higher score for their first vault compared to the second, the widest difference being 1.400 points (O.S. had a 1.400-point higher final score for her second vault, while M.S. received a 1.400-point higher final score for her first vault). We can also see that 4 gymnasts (C.J., S.G., B.E. and C.O.) have relatively close differences between their 3 scores (lower than 0.400 points), 2 gymnasts have differences of 0.600 points and 0.700 points, other 2 competing gymnasts have wider differences: O.S. has 1.200 points (-0.200 points difference between D-scores and -1.400 points difference between final scores), and M.S. has 1.000 point (0.400 points difference between D-scores and 1.400 points difference between final scores).

The results at the Doha 2018 World Championships are represented in Figure 17 and show the following: 6 gymnasts performed a first vault with a higher degree of difficulty, the widest difference between the two vaults being 0.600 points and only one gymnast succeeded in receiving the same score for both vaults; 2 gymnasts had a better execution on their first vault, and 6 gymnasts, on their second vault, the widest difference being -0.800 points (the second vault had a better execution than the first); regarding the differences between final scores, 4 gymnasts had a higher final score for their first vault than for the second, the widest difference being -1.100 points. We also see that there are wide differences between the 3 scores of most gymnasts, but P.R.Y. has the widest difference of 1.1 points.

Figure 18 shows the results achieved at the Stuttgart 2019 World Championships and we can notice the following: 5 gymnasts had a first vault of a higher difficulty value, the widest differences between the two vaults being 0.800 points (the first vault was more valuable) and -0.600 points (the second vault was more difficult); 5 gymnasts had a better execution on their first vault and 3 gymnasts had a better execution on their second vault, the widest difference being -1.000 point (the second vault was better than the first in terms of 
execution); concerning the final score difference, 6 gymnasts received a higher final score for their second vault compared to the first, the widest difference being 0.667 points. We can also see that the differences between the 3 scores are wider for the majority of gymnasts, but one in particular (Y.S.) has the widest difference of 1.800 points.

Analysing the 4 figures and the quality of execution, we can say that $70 \%$ of athletes prefer a first vault with a higher degree of difficulty. However, in terms of execution score, the first vault does not have to be the best. While only $47 \%$ of gymnasts received a higher Escore for the first vault, 53\% received a higher final score for their second vault.

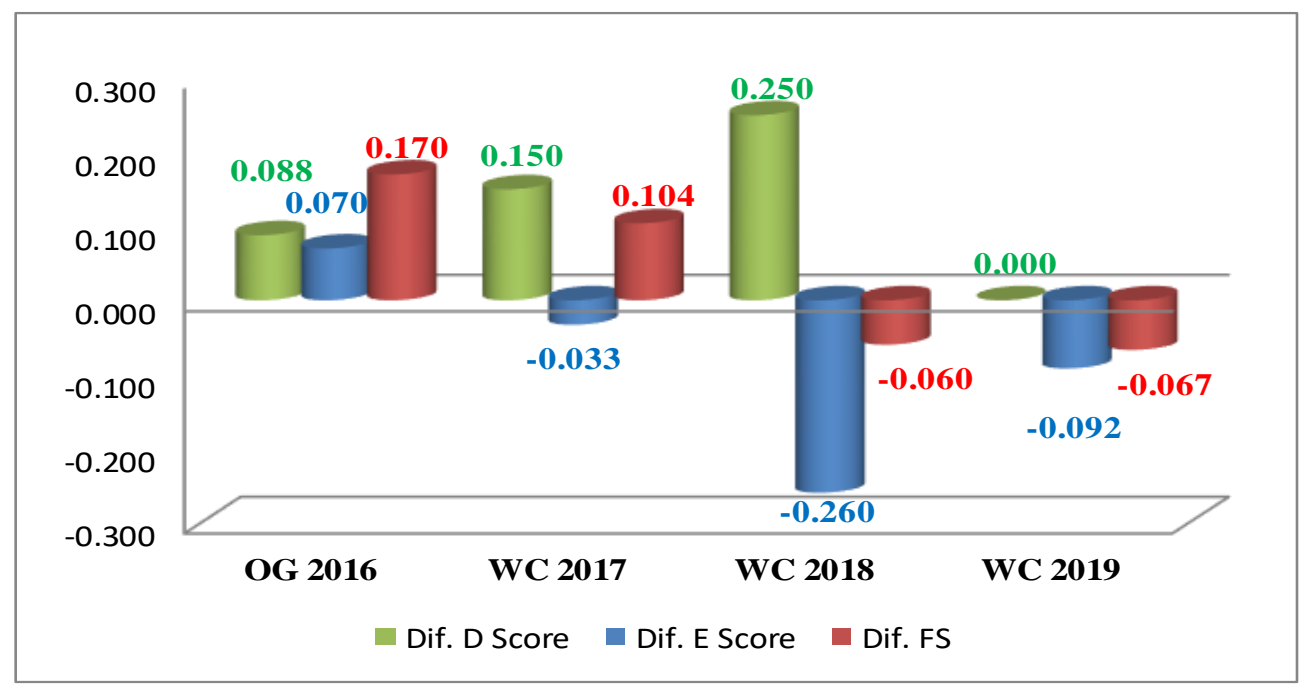

Figure 19. Average differences for each competition

Figure 19 shows the average differences between D-scores for the first and second vaults as well as between E-scores for the first and second vaults. We can see the average differences between final scores for the first and second vaults in each competition. We can also notice that these averages are rather balanced. The only competition with a wider score gap was the Doha 2018 World Championships, where the average D-score was 0.250 points (the first vault had a higher degree of difficulty) and the average E-score was -0.260 (the second vault was better executed).

\section{Conclusion}

In order to achieve an objective, efficient and valuable analysis, we must point out the extensive contribution of the studied bibliography, the thoroughness of the collected data and the expertise of our research team.

Concerning the athlete-effort relationship in Women's Artistic Gymnastics - Vault event addressed in the first part of our research, we believe that short-term and long-term adaptation, de-adaptation and re-adaptation, as well as overtraining, are inevitable phases during the career of any athlete and coach. However, the way in which we can overcome or avoid situations that can fragment or interrupt the sports training activity depends only on the specialist's level of professionalism. 
Following the analysis performed on the subjects of this research during the four years of study, we can conclude that the most complete athletes have at least two vaults of high technical value and increased difficulty in their sports portfolios. Considering the data collected over the four-year period and quantifying the gymnasts who participated in the world's most important competitions, we can certainly say that the number of highly valuable athletes is not large: there are only 18 gymnasts from only 12 countries.

The share of vault groups performed by the participants in this study leads to the following ranking: group 2, group 5, group 4 and group 3. Group 1 is completely missing from the variety of vaults performed by finalist gymnasts.

During apparatus finals in all four competitions, gymnasts performed ten vaults (which are also mentioned in the present paper). Only 3 gymnasts (from the US, IND and PKR) performed very difficult vaults with a D-score that was better than that of other finalists. However, it has been proven not to be enough to ensure the performer's victory in the competition. The only successful gymnast was the US representative, who not only performed a difficult vault but also had a good execution.

Following the purpose of our paper, we managed to identify the most valuable gymnast in this Olympic cycle, namely the representative of the United States. By far, this athlete is the most complete performer in the Vault event. The gymnast succeeded in executing an extremely difficult vault in competition, a technical achievement that bears her name.

As a result of the conducted research, we can finally draw a profile of the winning gymnast in the Vault event. The athlete must be complete in terms of acquired motor skills and show great courage, tenacity, kinaesthetic balance, good spatial-temporal orientation and, last but not least, elegance of performance. Only by having such a presence during the finals of major sports events can gymnasts hope to win a place on the podium in future competitions.

\section{Authors' Contributions}

All authors have equally contributed to this study and should be considered as main authors.

\section{References}

Atikovic, A. (2012). New regression models to evaluate the relationship between biomechanics of gymnastic vault and initial vault difficulty values. Journal of Human Kinetics, 35(1), 119-126. https://dx.doi.org/10.2478\%2Fv10078-012-0085-6

Budgett, R. (1998). Fatigue and underperformance in athletes: The overtraining syndrome. British Journal of Sports Medicine, 32(2), 107-110. https://dx.doi.org/10.1136\%2Fbjsm.32.2.107

Farana, R., \& Vaverka, F. (2012). The effect of biomechanical variables on the assessment of vaulting in top-level artistic female gymnasts in World Cup competitions. Acta Gymnica, 42(2), 49-57. https://doi.org/10.5507/AG.2012.012

Fernandes, S. M. B., Carrara, P., Serrao, J. C., Amadio, A. C., \& Mochizuki, L. (2016). Kinematic variables of table vault on artistic gymnastics. Revista Brasileira de Educação Física e Esporte, 30(1), 97-107. https://doi.org/10.1590/1807-55092016000100097 
FIG. (2013). 2013-2016 Code of Points: Women's Artistic Gymnastics. https://www.gymtranet.dk/media/1178/cop2013.pdf

FIG. (2016). 2017-2020 Code of Points: Women's Artistic Gymnastics. https://eugymnastics.files.wordpress.com/2017/04/cop_wag_2017-2020_ici-e1.pdf

Fry, R. W., Morton, A. R., \& Keast, D. (1992). Periodisation and the prevention of overtraining. Canadian Journal of Sports Science, 17(3), 241-248. WOS: A1992JK79300013

Hedbavny, P., \& Kalichova, M. (2015). Optimization of velocity characteristics of the Yurchenko vault. Science of Gymnastics Journal, 7(1), 37-49. WOS: 000362425500005

Kalinski, S. D., Atikovic, A., Jelaska, I., \& Milic, M. (2016). Performance analysis of female gymnasts' vault in elite competitions from 2008 to 2015. Science of Gymnastics Journal, 8(2), 109-123. WOS: 000393495800002

Kalinski, S. D., Jelaska, G., \& Atikovic, A. (2017). Elite female vault finals from 20082016. Acta Kinesiologica, 11(1), 62-66. WOS: 000405698300010

Meeusen, R., Duclos, M., Gleeson, M., Rietjens, G., Steinacker, J., \& Urhausen, A. (2006). Prevention, diagnosis and treatment of the overtraining syndrome: ECSS position statement "Task Force”. European Journal of Sport Science, 6(1), 1-14. https://doi.org/10.1080/17461390600617717

Platonov, V. N. (2015). Periodizarea antrenamentului sportiv - Teoria generală și aplicațiile ei practice [Sport training periodisation - General theory and its practical applications]. Discobolul.

Potop, V. (2013). E-learning by computer video analysis the key elements of sports technique of Yurchenko vault in women's artistic gymnastics. In I. Roceanu (Ed.), Proceedings of the $9^{\text {th }}$ International Scientific Conference "eLearning and Software for Education", Bucharest, April 25-26, 2013 (Vol. 3, pp. 151-158). Editura Universității Naţionale de Apărare "Carol I". DOI: 10.12753/2066-026X-13-239

Potop, V., \& Toma-Urichianu, S. (2018). Analysis of physical training influence on the technical execution of Yurchenko handspring vault. In V. Manolachi, C. V. Rus, \& S. Rusnac (Eds.), 3rd Central and Eastern European LUMEN International Conference "New Approaches in Social and Humanistic Sciences", Chișinău, Republic of Moldova, June 8-10, 2017 (pp. 392-403). Iași, Romania: LUMEN Proceedings. https://doi.org/10.18662/lumproc.nashs2017.34

Prassas, S., Kwon, Y.-H., \& Sands, W. A. (2006). Biomechanical research in artistic gymnastics: A review. Sports Biomechanics, 5(2), 261-291. https://doi.org/10.1080/14763140608522878

Rojas-Barrionuevo, N.A., Vernetta-Santana, M., Alvariñas-Villaverde, M., \& López-Bedoya, J. (2017). Acute effect of acrobatic jumps on different elastic platforms in the muscle response evaluated through tensiomyography. Journal of Human Sport and Exercise, 12(3), 728-741. http://dx.doi.org/10.14198/jhse.2017.123.17

Sands, W. A., \& McNeal, J. R. (2002). Some guidelines on the transition from the old horse to the new table. Technique, 22, 22-25.

Stroescu, S. A. (2015). Kinematic biomechanical analysis of "Handspring forward with 11/2 tucked salto forward" vault. In Proceedings of the $4^{\text {th }}$ International Congress of Physical Education, Sports and Kinetotherapy, Bucharest, Romania, June $11^{\text {th }}-14^{\text {th }}, 2014$ (pp. 447452). Bologna: Medimond. WOS: 000360246100076

Uzunov, V. (2010). Qualitative description of the ideal Yurchenko layout vault technique. Gym Coach: Journal of Coaching \& Sport Science in Gymnastics, 4, 1-6. DOI: 10.13140/RG.2.1.1412.2728

Vain, A., \& Kums, T. (2002). Criteria for preventing overtraining of the musculoskeletal system of gymnasts. Biology of Sport, 19(4), 329-345. WOS: 000180413800005 